\title{
FOLLICULITIS DECALVANS AND LICHEN SPINULOSUS
}

\author{
a clinical combination *
}

FR.ANCIS EUGENE SENEAR, B.S., M.D.

Associate and Acting Head of The Department of Dermatology, University of Illinois, College of Medicine

CHICAGO

The depilating folliculitides compose a complex and little understood group of dermatoses, as is indicated by the variety of names given to these conditions by different authors. The terms folliculitis decalvans and pseudopelade, with which we are most familiar, usually call to mind processes producing baldness of the scalp alone. The literature shows, however, that a clinical picture similar to that of folliculitis decalvans may be seen on other hairy parts of the body, either in association with the disease on the scalp, or independently. Pringle, ${ }^{1}$ Robinson ${ }^{2}$ and others have described cases in which folliculitis decalvans of the scalp has been associated with a similar pathologic process in other parts. Among those who have described a similar picture in hairy parts other than the scalp, and without any accompanying involvement of the scalp, are Mewborn, ${ }^{3}$ Darier, ${ }^{4}$ and Arnozan, ${ }^{5}$ the latter, under the title "Depilating Folliculitis of the Limbs," describing a condition which he said he would have likened to pseudopelade if it had occurred on the scalp. Lastly, we are familiar with lupoid sycocis of Milton or ulerythema sycosiforme of Unna, ${ }^{6}$ and ulerythema ophryogenes of Taenzer and Unna, ${ }^{7}$ two conditions which have much in common with folliculitis decalvans.

This paper is not concerned, however, with folliculitis decalvans associated with similar lesions elsewhere, but rather with the combination of folliculitis decalvans on the scalp, and lichen spinulosus on the body. Attention was first given to this combination when Graham Little ${ }^{8}$ presented a case before the Dermatological Section of the Royal Society of Medicine in 1915, and it is interesting to note that the only other two cases on record were seen in Great Britain

* Read before the Section on Dermatology at the Seventy-First Annual Session of the American Medical Association, New Orleans, April, 1920.

1. Pringle: Brit. J. Dermat. 7:117, 1895.

2. Robinson: Jour. Cutan. \& Gen.-Urin. Dis. 23:268, 1905.

3. Mewborn: Jour. Cutan. \& Gen.-Urin. Dis. 22:589, 1904.

4. Darier: Ann. de dermat. et syph. 32:58, 1901.

5. Arnozan: Ann. de dermat. et syph. 23:491, 1892.

6. Unna: Monatsh. f. prakt. Dermat. 8:134, 1889.

7. Taenzer: Monatsh. f. prakt. Dermat. 9:197, 1889.

8. Little: Brit. J. Dermat. 27:183, 1915. 
in the same year, the second one being presented before the same society by Dore, ${ }^{9}$ while the third one was described in detail by Wallace Beatty ${ }^{10}$ of Dublin.

\section{REPORT OF CASES}

CASE 1.-History.-Little's patient was a woman, 55 years of age, sent to him by Dr. Lassueur of Laussane, who wrote "The aspect of the skin seems to me to recall lichen spinulosus, especially the lesions of the flexual folds and the armpits. But the condition of the scalp is very unusual, and I am altogether embarrassed to make a diagnosis which fits in with the skin affection." The condition had begun ten years before, when the patient developed an inflammatory condition of the vertex of the scalp which resulted in a slow shedding of the hair and the develapment of bald patches. Subjective symptoms were lacking, and the trouble was ignored. Five months before Little saw the patient a similar, although much more rapid, inflammation accompanied by great itching. became apparent on the side and front of the scalp, and the hair came out in handfuls; at the same time an itchy eruption was manifest in the axillae, groins and the flexures of the elbows. In these positions there was a folliculitis in grouped patches with a general resemblance to lichen spinulosus, while on the back and on the exterior surfaces of the upper arms there was a diffuse. slightly spiny folliculitis, also itchy and reddened. The hair of the scalp. axillae and groin had been almost entirely destroyed, but the atrophy apparent in the scalp was not yet present in the axillae and groin. Little said that the condition on the scalp was obviously familiar under the name of folliculitis lecalvans. He had thought of Darier's disease, but the distinct alopecia and the exclusive follicular location of the lesions in the case excluded that diagnosis.

Discussion of Case.-In the discussion which followed the case presentation, all of the speakers - Pringle, Morris, Adamson, Sequeira and MacLeod agreed that the condition on the scalp was folliculitis decalvans, but there was a considerable difference of opinion as to the nature of the eruption on the body, some of the speakers considering it a possible early form of Darier's disease, while others were convinced that it was not. In a later discussion, however, Little asserted definitely that it was a true lichen spinulosus.

CASE 2.-History.-Dore's patient was also a woman, aged 43. The case bore a rather close resemblance to that of Little's. A typical folliculitus decalvans had been present for two years. Nine weeks before she was shown she developed a follicular eruption indistinguishable from lichen spinulosus on the abdomen, back, chest, thighs, neck and ears. This eruption consisted chiefly of minute, scattered, skin-colored, acuminate or spiny noninflammatory papules; a few were larger, and reddened or excoriated.

Discussion of Case.-In discussing this case, Little stated that the body lesions in his case were more definitely spiny than those in Dore's, and that he considered the spiny eruption in Dore's case a coincident lichen scrofulosorum, while Adamson felt that all that could be said about the condition on the body was that it was a folliculitis.

CASE 3.-History.-Beatty's ${ }^{10}$ case was carefully investigated and reported in detail. The patient, a woman of 43 years, had an eruption on the scalp and upper part of the body, presenting a combination of cutaneous symptoms unlike any combination which he had seen previously. He said only the scalp sug-

9. Dore: Brit. J. Dermat. 27:295, 1915.

10. Beatty: Brit. J. Dermat. 27:331, 1915. 
gested folliculitis decalvans; the condition on the body resembled lichen spinulosus as occasionally seen in children, though of a coarser kind. The hair had begun to fall ten years previously, coming out in patches, gradually, without soreness, until after some years an almost universal baldness was produced. Itching of the head was at times troublesome. The eruption on the body began a month before Beatty saw the patient, appearing as a "roughness of the skin." The upper part of the chest anteriorly was first affected, but the condition spread and similar roughness appeared on the scalp.

Examination.-This revealed a scalp of cicatricial aspect, smooth and bald, throughout the greater part. Here and there were small, hard islets of follicular prominences, and formed by an accumulation of dry, horny material, some of them were pierced by short hairs. These groups of follicular plugs developed in association with the eruption on the body. On the neck, body and limbs were groups of follicular elevations, some with prominent horny spines such as are seen in lichen spinulosus of children. This eruption was widespread, but there were few lesions on the lower portion of the trunk. They were all follicular, there was a universal tendency to grouping, and the color varied from flesh color to reddish brown. The spines in the smaller lesions were fine and hairlike, and blunt in the larger lesions. They could be picked out intact, leaving a gaping folliculiar opening.

In his remarks, Beatty states that he was struck by the resemblance of his case to that of Graham Little's, a history of shedding of the hair dating back some years, followed by an acute condition like lichen spinulosus on the body. Little's and Dore's cases and his own had led him to believe that the combination of these two conditions, which he had at first regarded as merely accidental, constituted a clinical unity. He proposed calling this combination of atrophic baldness of the scalp and lichen spinulosus "Lassueur's and Graham Little's syndrome." Tissue examination in this case showed the "corps rond" described in Darier's disease, the "psorosperms" being few and discovered only after the study of a large number of sections. As Webber says, if these bodies are to be considered pathognomonic of this disease, then his case must be regarded as an atypical Darier's disease.

CASE 4.-History.-My patient was a woman, aged 30 , seen in Dr. W. A. Pusey's practice, in October, 1919. The disease began when she was 9 years of age. At that time her hair began to fall rather rapidly, the alopecia being permanent. This alopecia has been slowly progressive since that time. Eight years ago she developed an eruption over the back which she says was similar to the present attack, but it cleared up spontaneously. The present exacerbation began four or five months before the patient was seen. The first lesions appeared over the nape of the neck, followed by others over the occipital region, shoulders and back. This condition was complicated in September, when a number of boils appeared over the scalp and back. The hair had been shed rapidly again after this eruption appeared on the body. The patient's personal history disclosed nothing of interest. Her general health had always been good, and she had never had any serious illness. She suffered from chronic constipation, but had used laxatives regularly and had a daily bowel movement. Menstruation was regular and normal. The Wassermann reaction was negative.

Examination.-This disclosed two clinical pictures. The scalp showed an extensive alopecia, most of the hair having disappeared, while the remaining hair was found in patches, as shown in the photograph. The skin of the bald areas showed an extreme atrophic scarring of the type seen in folliculitis decalvans. The process which had produced this atrophy was still active, 
numerous follicular papules and a few pustules being present. The other eruption, involving the nape of the neck, lower occipital region, shoulders, back and upper arms, consisted of variously sized groups of follicular lesions. The individual lesions varied from reddish follicular papules, slightly elevated, to definitely elevated and spinous lesions, some of them having rather long, slender spines. In the largest patches the lesions had slightly inflammatory areolae, so that the group picture showed an erythematous background with elevated follicular lesions. In the smaller groups the erythematous background was lacking, showing it to be secondary. Removal of one of the spinous lesions left a dilated follicular orifice. The lesions varied from a grayish to a reddish color, while the group was dull red. The patient, who was refractory, refused biopsy, and passed from observation before any therapeutic attempts could be made.

\section{SUMMARY AND COMMENT}

All of these four cases occurred in women, aged, respectively, 55, 43,43 and 30 years. In all, folliculitis decalvans was of long standing (ten, two, ten and twenty-one years, respectively), followed by the rather sudden development of a follicular eruption of the body whose clinical picture was that of lichen spinulosus. In all cases the condition on the scalp was obviously folliculitis decalvans, but the body eruption was more puzzling. In the discussion of Little's case, an early Darier's disease was considered, but Little had been able to rule this out to his own satisfaction, and in a later discussion stated definitely that the condition was lichen spinulosus. Dore considered the eruption in his case to be clinically indistinguishable from lichen spinulosus, as did Beatty in his case, although it will be recalled that the histologic picture suggestive of Darier's disease was disturbing. In my case no suspicion of Darier's disease could be entertained. The exclusive follicular location of the papules, the distribution of the eruption, the extreme alopecia, the lack of a greasy seborrheic element, the grouping and the spinous character of the lesions readily eliminate that disease. I am convinced that this combination is not to be regarded as merely an unusual keratosis follicularis.

No attempt has been made to explain the association of these two conditions, and this is not surprising when we consider that we are dealing with two conditions, each of obscure etiology. Coincidence would scarcely serve as an explanation, since each of them is an uncommon disorder. It is difficult to consider the eruption on the body as folliculitis decalvans, since in none of the four cases was there any atrophic scarring in the body lesions, as is the case when folliculitis decalvans affects parts other than the scalp. Furthermore, the body eruption was too acute.

I wish to suggest, however, one hypothesis which is founded on a comparative basis. We are familiar with other follicular eruptions, which are looked on as manifestations of the activity of toxins secrefed 


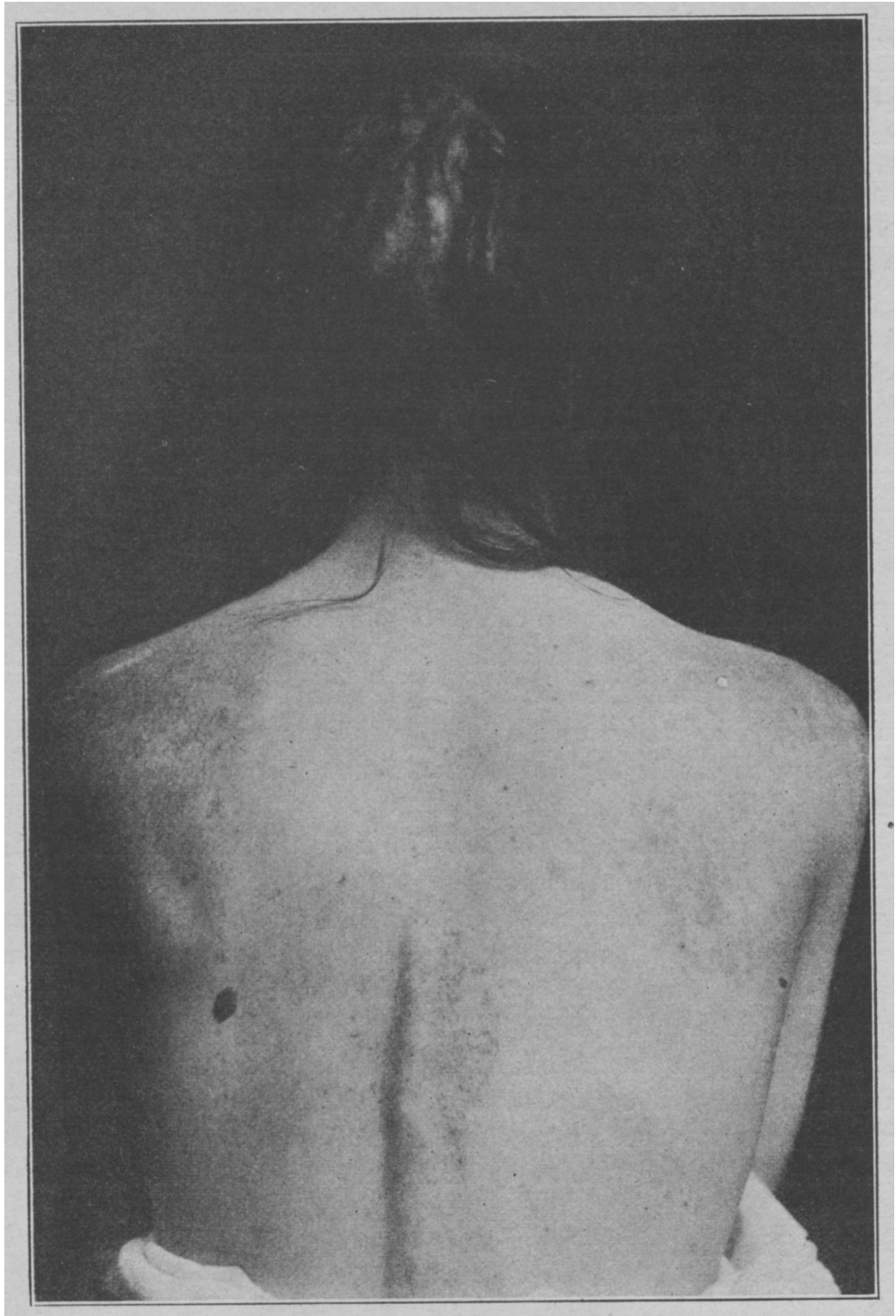

Mopecia and ermption wer hack, neck and shothlers in Case 4. 
by infectious organisms affecting distant parts of the body. The most familiar example of this kind is the lichen scrofulosorum type of tuberculid. More recently we have become acquainted with the group of trichophytids, first described by Jadassohn in 1911, consisting for the most part of lichenoid eruptions occurring on the body of children affected with trichophytosis capitis, usually kerion celsi. In a number of these cases the eruption assumed a type clinically indistinguishable from lichen spinulosus, as shown by Jadassohn, ${ }^{11}$ Bloch, ${ }^{12}$ Guth, ${ }^{13}$ Rasch ${ }^{14}$ and others.

In the condition under consideration we have some points in common with the above conception of the etiology of lichen scrofulosorum and lichenoid trichophytids; folliculitis decalvans being almost certainly due to a chronic infective process, which, theoretically at least, might be able to elaborate toxins responsible for the production of lichen spinulosus. In support of this view may be offered the opinion of Adamson, ${ }^{15}$ who is probably best acquainted with lichen spinulosus; he suggests that a toxic etiology is the most plausible one for the condition. Furthermore, in at least two of the cases (Beatty's and my own), the process on the scalp, as evidenced by the alopecia, had become more active at the time of appearance of the lichen scrofulosorum; and we know that in the case of the tuberculids, the eruption often appears at a time when the tuberculous process has been lighted up by some factor, as in the case of lichen scrofulosorum following measles. The above hypothesis is offered, it should be understood, only as a suggestion, for I had no opportunity to study the patient with this view in mind.

In conclusion, I should like to say that this paper was offered to call attention to this combination of clinical conditions in the hope that recognition and study of other cases might result in a better understanding of its significance.

\section{ABSTRACT OF DISCUSSION}

Dr. J. M. KIng, Nashville, Tenn.: I had a patient who had lichen spinulosus, but I do not recall that she had any disturbance of the hair or folliculitis. The hair growth was poor and thin; she complained of itching but had no scalp involvement. The diagnosis in this case was confirmed by $\mathrm{Dr}$. George MacKee and Dr. Howard King.

Dr. F. W. Cregor, Indianapolis: We do not have as much folliculitis decalvans in this country as in Europe. I recall seeing many boys in the

11. Jadassohn: Autoreferat i, Cor.-B1. f. schweiz. Aerzte, 42:24, 1912.

12. Blocki: Die Allgemein-pathologische Bedeutung der Dermatomykosen, Halle, p. 82, 1913.

13. Guth: Arch. f. Dermat. u. Syph. 118:856, 1914.

14. Rasch: Brit. J. Dermat. 28:9, 1916.

15. Adamson: Brit. J. Dermat. 17:39, 1905. 
clinics there begging to be relieved of the scars following this disease that they might emigrate to America. I have not observed lichen spinulosus in any cases of folliculitis decalvans. I have observed, however, lichen spinulosus following lichen ruber planus in two patients, both of whom had received arsenic for more than 120 days. I think that arsenical medication had something to do with the process in Dr. Senear's case.

Dr. Walter J. Highman, New York: I had a patient with what I thought was pityriasis rubra pilaris on the body and patches on the head of what seemed to be alopecia areata but which proved to be pityriasis rubra pilaris.

Dr. Oliver S. Ormsby, Chicago: In November, 1919, I presented a patient before the Chicago Dermatological Society with a condition which was practically identical with that reported by Dr. Senear. It was presented as an example of folliculitis decalvans and lichen spinulosus. I think five cases are now on record. The patients all had a similar history and probably represent a disease group which has not heretofore been reported.

Dr. Francis E. Senear, Chicago: Dr. Ormslby's case and mine corresponded in nearly every detail in the clinical picture, except that the scalp involvement in my case was more extensive than in Dr. Ormsby's case. Arsenic might well furnish a basis for the development of lichen spinulosus. In the English literature there is not infrequent reference to the development of spinous lesions in lichen planus, similar in character to those of lichen spinulosus. It is possible that Dr. Cregor has seen that type of lichen planus, but it does not seem probable that the treatment he mentioned would have cleared up the cases so readily and permanently bad they been true lichen planus lesions. 